\title{
Treatment of Hydrocephalus Using Saphenous Vein Homograft
}

\author{
T. E. UDWADIA \\ From J.J. Group of Hospitals and Bai Jerbai Wadia Hospital for Children, Bombay, India
}

The literature abounds with a multitude of surgical procedures for hydrocephalus, and CSF has been shunted in every conceivable manner. The very number of these operations is an eloquent testimony to their inadequacy. In 1908, Payr (quoted by Benson et al., 1962) described an operation whereby the CSF was shunted from the lateral ventricle into the jugular vein, with the help of tubes made from the hardened arteries of calves. However, due to regurgitation of blood into the lateral ventricle the operation soon fell into disrepute. Almost half a century later, thanks to advances in the science of bioengineering, Payr's principle was revived in the Spitz-Holter and the Pudenz-Heyer procedures. The introduction of the Spitz-Holter and PudenzHeyer valves has to a large extent standardized the treatment of hydrocephalus in the West. In India and other developing countries dire financial stringency precludes the use of these valves, and enforces the adoption of alternative operative procedures as an economic necessity.

It is the purpose of this paper to present the results of treatment in 70 cases of hydrocephalus in infancy and childhood. The occasional child who could afford the 'luxury' of a Spitz or Pudenz valve is not included in this series. Table I shows the mode of treatment of these 70 cases: 55 were treated by 'conventional' procedures, and 15 by a new operation whereby CSF is shunted into the venous circulation using a reversed, valvebearing segment of the saphenous vein. In every case subjected to operation, it was established that the hydrocephalus was progressive.

\section{Results of Treatment by 'Conventional' Pro- cedures}

Table II depicts the depressing results obtained by ventriculo-peritoneal, theco-peritoneal, thecoureteric, and ventriculo-sagittal sinus shunts.

Peritoneal shunts. Though achieving only

Received November 12, 1968.
20 arrests in 46 cases treated by peritoneal shunts, this procedure occasionally gives surprisingly gratifying results in individual cases, and in our experience is the best of the conventional procedures. Of the 21 patients who were re-explored for recurrence of symptoms after peritoneal shunts, the shunt stopped functioning in the majority, due to omentum enveloping the tube. We now carry out a meticulous excision of the omentum as an essential part of this procedure. In a few cases in which peritoneal shunts were carried out, in addition to the tube used for the CSF shunt,

TABLE I

Types of Shunt Used

\begin{tabular}{|c|c|c|c|c|c|c|c|c|}
\hline \multicolumn{8}{|c|}{ Type of Shunt } & \multirow{2}{*}{$\begin{array}{c}\text { No. of Cases } \\
39 \\
7 \\
3 \\
6\end{array}$} \\
\hline $\begin{array}{l}\text { Ventric } \\
\text { Theco- } \\
\text { Theco- } \\
\text { Ventric }\end{array}$ & $\begin{array}{l}\text { llo-peri } \\
\text { seritone } \\
\text { ureteric } \\
\text { llo-sagi }\end{array}$ & $\begin{array}{l}\text { toneal } \\
\text { ttal sinu }\end{array}$ & $\begin{array}{l}\ldots \\
\ddot{1 s}\end{array}$ & $\begin{array}{l}\ldots \\
\cdots \\
\cdots\end{array}$ & $\begin{array}{l}\ldots \\
\cdots \\
\cdots \\
\cdots\end{array}$ & $\begin{array}{l}\cdots \\
\cdots \\
\cdots\end{array}$ & $\begin{array}{l}. \\
\cdots \\
. \\
.\end{array}$ & \\
\hline Total & . & . & . & $\cdots$ & . & . & $\cdots$ & 55 \\
\hline \multicolumn{6}{|c|}{ Ventriculo-jugular with saphenous vein } & . & $\cdots$ & 15 \\
\hline Total & . & .. & .. & . & .. & . & .. & 70 \\
\hline
\end{tabular}

TABLE II

Results of Treatment

\begin{tabular}{l|c|c|c|c|c|c}
\hline Operation & $\begin{array}{c}\text { No. of } \\
\text { Cases }\end{array}$ & Arrest & $\begin{array}{c}\text { Re- } \\
\text { explored }\end{array}$ & $\begin{array}{c}\text { No } \\
\text { Improve- } \\
\text { ment }\end{array}$ & $\begin{array}{c}\text { Lost to } \\
\text { Follow- } \\
\text { up }\end{array}$ & Dead \\
\hline $\begin{array}{c}\text { Ventriculo- } \\
\text { peritoneal }\end{array}$ & 39 & 17 & 21 & 14 & 4 & 4 \\
$\begin{array}{c}\text { Theco- } \\
\text { peritoneal }\end{array}$ & 7 & 3 & 2 & 1 & 2 & 1 \\
$\begin{array}{c}\text { Theco- } \\
\text { ureteric }\end{array}$ & 3 & 1 & - & - & 1 & 1 \\
$\begin{array}{c}\text { Ventriculo- } \\
\text { sagittal } \\
\text { sinus }\end{array}$ & 6 & - & 2 & 5 & 1 & 1 \\
\hline Total & 55 & 21 & 25 & 20 & 8 & 7 \\
\hline
\end{tabular}




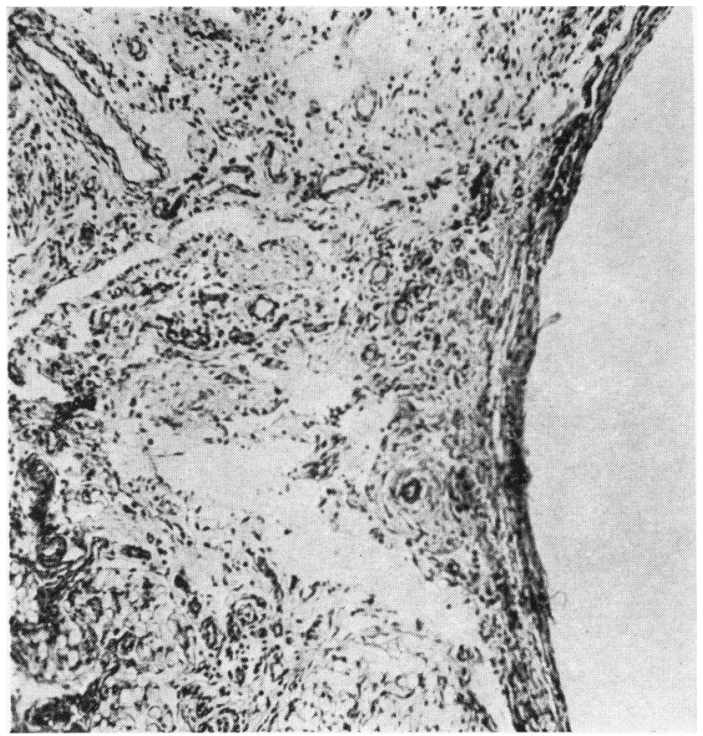

FIG. 1.-Photomicrograph of omental and peritoneal reaction around portex tube through which CSF was shunted into the peritoneal cavity. The tube was removed when symptoms recurred 6 months after operation. $(\times 60$.

another small piece of tubing, not connected to the CSF pathway, was fixed in the peritoneum. Fig. 1 and 2 show that the omental and peritoneal reaction was far more intense around the tube through which CSF entered the peritoneum than around the 'dummy' tube. From a study of the cases re-explored, it was also established that the omental and peritoneal reaction was most intense in those cases which had a high protein content in the CSF before operation.

Ureteric shunts. Our experience has been limited to only 3 cases. We were put off by the condition in which the child who died was brought for readmission, in gross fluid and electrolyte deficiency, sequelae of this operation which are strongly aggravated by our climatic conditions.

Sagittal sinus shunts have had uniformly hopeless results.

\section{Experiences with New operation for Hydro- cephalus}

Fig. 3 shows a diagrammatic representation of a different operation which has been carried out in 15 cases of progressive hydrocephalus. Instead of using the expensive prosthetic valve, a saphenous vein graft is reversed and interposed between the lateral ventricle and the jugular vein. The valve

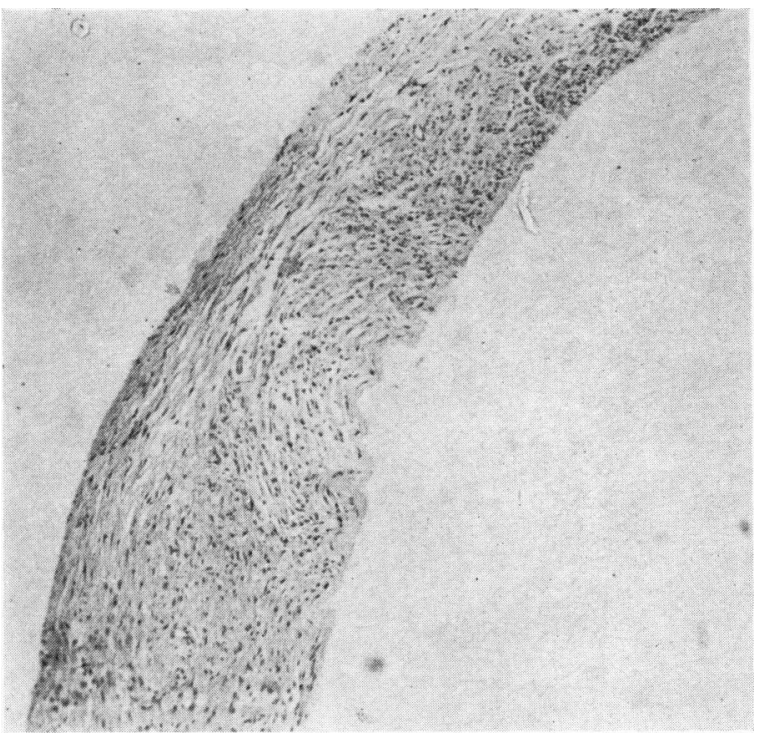

FIG. 2.-Reaction around 'dummy' tube inserted in the same peritoneal cavity which shows very slight reaction as compared to Fig. $1 . \quad(\times 60$.

of the saphenous vein prevents reflux of blood from entering the lateral ventricle (Udwadia, 1968).

Before placing this operation in the clinical field, certain experiments were carried out. A cardiac catheter was inserted up the cubital vein to lie with its tip at the junction of the jugular and

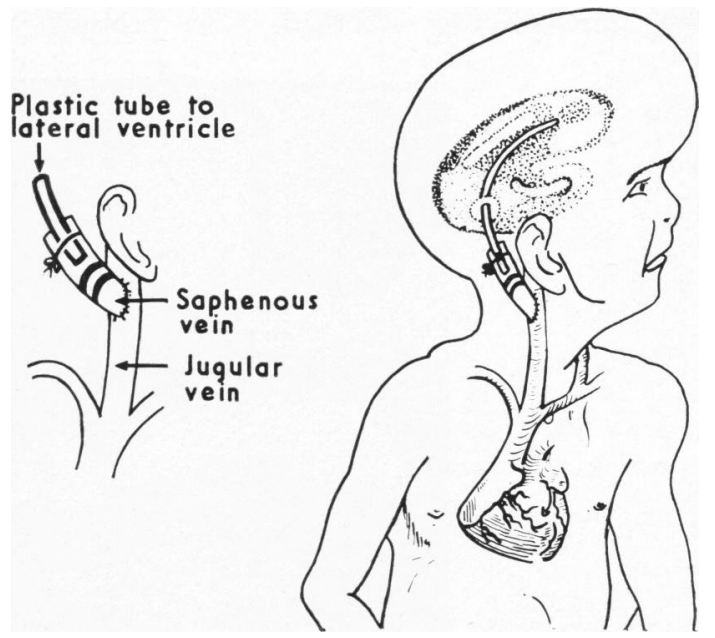

FIG. 3.-Diagrammatic representation of the new operation. CSF from the lateral ventricle is shunted via a saphenous vein graft into the internal jugular vein. The vein is so placed that the valve faces the anastomosis, preventing reflux of blood from entering the lateral ventricle. 


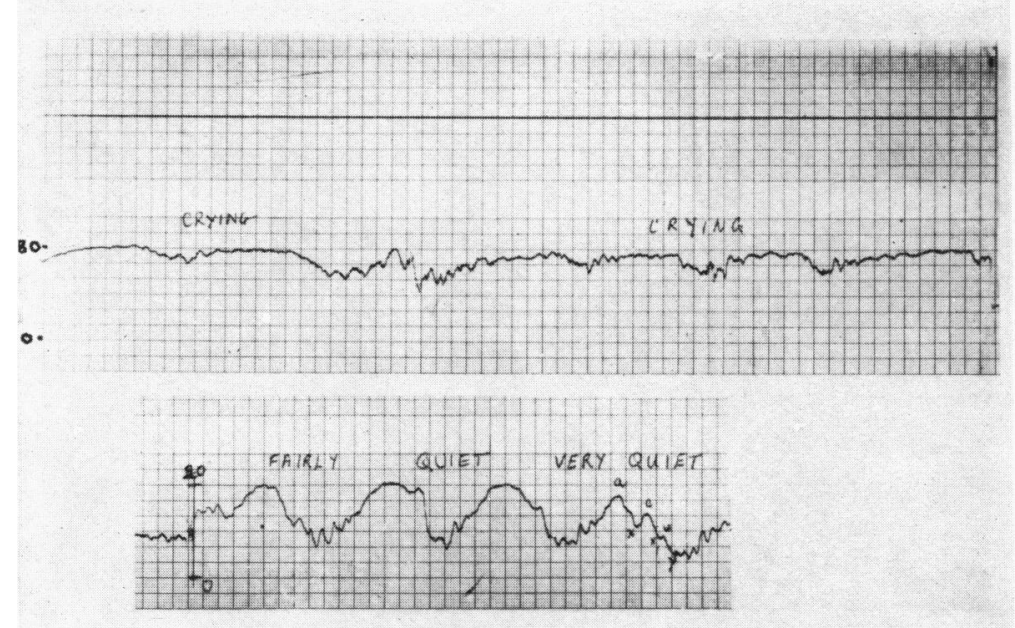

FIG. 4.-The maximum pressure recorded in the straining infant's jugular vein was $80 \mathrm{~mm}$. $\mathrm{Hg}$.

innominate veins, and pressure tracings in infants and children under various conditions of crying and straining were recorded. The maximum pressure attained in the jugular vein while the child was made to strain and cry was in the region of $80 \mathrm{~mm}$. $\mathrm{Hg}$ (Fig. 4). In another series of experiments saphenous veins obtained from fresh cadavers were subjected to manometric studies, and the ability of the valves to withstand pressure was assessed. Fig. 5 shows the cannuiated saphenous vein subjected to pressure using a dye for perfusion. Through the $\mathrm{Y}$ connexion pressure within the vein was simultaneously recorded. The pressure at which the dye trickled past the saphenous valve was considered the critical pressure at which the valve became incompetent. Fig. 6 shows that the saphenous valve could withstand a pressure of $800 \mathrm{~mm}$. Hg.

\section{Operative Technique}

The donor saphenous vein was obtained from an adult, usually the child's mother, through a small incision above the knee, making sure, by injecting saline into the vein against the flow of blood, that the segment of vein removed contained at least one competent valve. The child was positioned with its neck

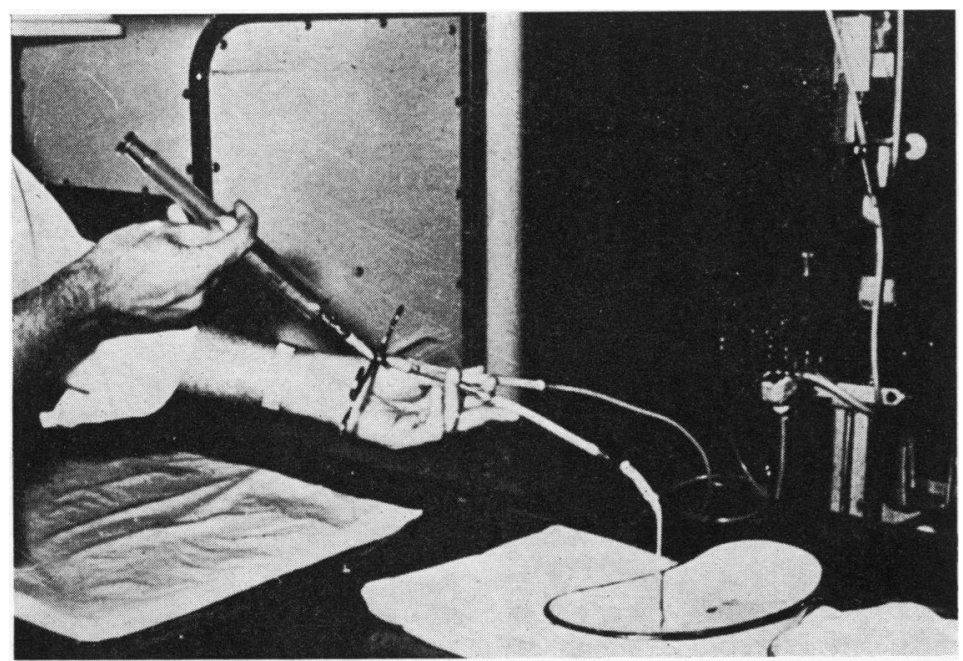

Fig. 5.-Fresh cadaveric saphenous vein being perfused with dye. Pressures simultaneously recorded through a $Y$ connexion. 


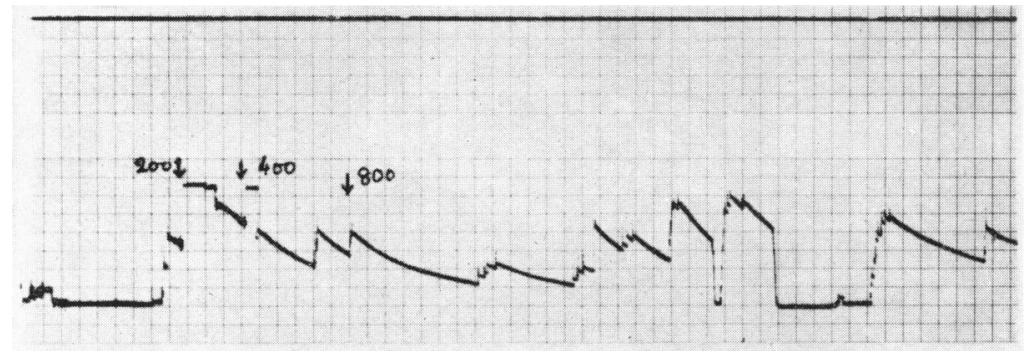

FIG. 6.-Manometric pressure studies of perfused saphenous vein showing that the valve can withstand a pressure up to $800 \mathrm{~mm}$. $\mathrm{Hg}$.

extended and the face turned to the left. Under general anaesthesia the right internal jugular vein was exposed through a vertical incision in the neck. The donor saphenous vein was anastomosed end-to-side to the child's jugular vein, making sure that the saphenous vein valve was facing the jugular vein. The anastomosis was carried out with 000000 atraumatic black silk. After the anastomosis was completed it was seen in each case that blood entered the saphenous vein, showing that the anastomosis was patent, and the blood stopped short at the saphenous valve, indicating that the valve was competent (Fig. 7). Through a curved incision in the scalp, as in the Spitz operation, the dura was exposed through a small trephine hole. A siliconized polyethylene tube with side openings for $5 \mathrm{~cm}$. from its tip was inserted through the dura into the lateral ventricle, and fixed in place by a pursestring stitch through the dura (Fig. 8). Through a subcutaneous tunnel the other end of the polyethylene tubing was brought out in the incision in the neck. The free end of the saphenous vein was telescoped on to the tubing and fixed on to it with firm ligatures (Fig. 9). It was made sure that the tubing and the vein constituted one smooth continuous channel without any excess length which could give rise to kinking of the vein. The incisions in the scalp and neck were closed in layers.

\section{Results}

Table III summarizes the early results in the 15 patients operated on so far. There was no mortality. One patient developed a continuous high temperature, starting 3 weeks after operation, and the shunt had to be dismantled when the fever could not be controlled by antibiotics for over 2 weeks. Of the 15 patients, 2 were post-meningitic, and the results were totally unsatisfactory in both. Of the 13 patients with 'congenital' hydrocephalus, 9 are asymptomatic with arrest of hydrocephalus, 2 had recurrence of symptoms after operation and are lost to follow-up, in 1 the shunt had to be dismantled due to infection, and 1 refused re-exploration after recurrence. Of the 9 asymptomatic patients, 1 needed a revision of the shunt because
TABLE III

Results of Ventriculo-jugular Saphenous Vein Shunts after Follow-ups from 3 months to $2 \frac{1}{2}$ years

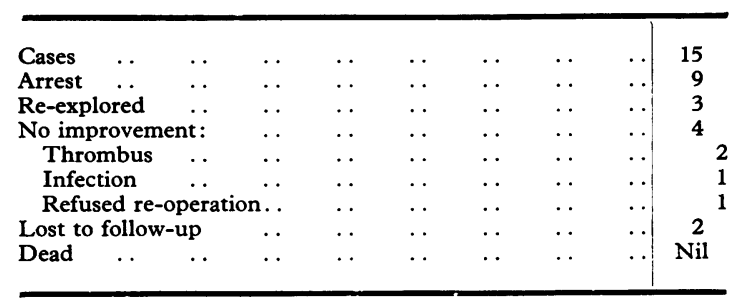

an excessively long segment of donor vein was becoming kinked.

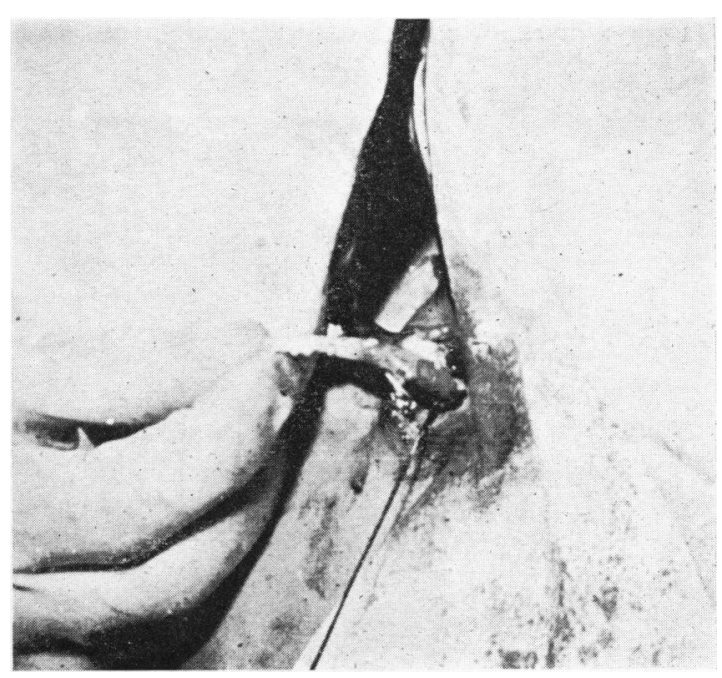

FIG. 7.-End-to-side anastomosis between the donor saphenous vein and the internal jugular vein. Blood has entered the saphenous vein showing that the anastomosis is patent, but stops short at the valve which is competent. 


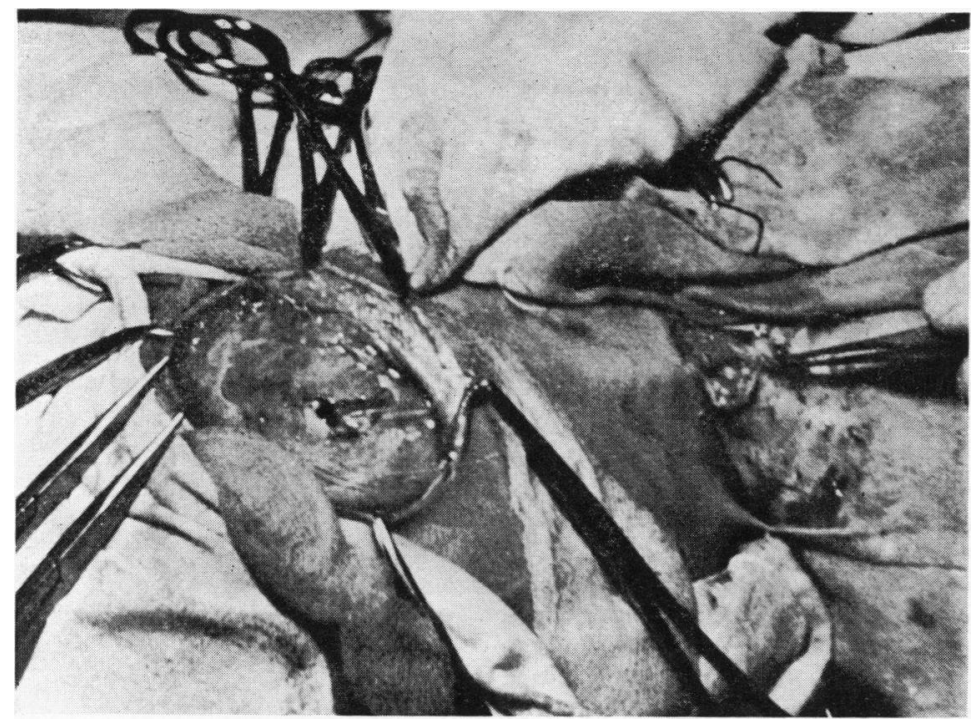

Fig. 8.-Through a burr hole in the skull, one end of a portex tube is inserted into the lateral ventricle. The burr is guttered at the site of emergence of the tube to prevent kinking. Through a subcutaneous tunnel the other end is brought out in the incision in the neck.

\section{Discussion}

Of the 55 patients subjected to peritoneal, ureteric, or sagittal sinus shunts, arrest occurred in 21 (38\%). This is indeed a depressing result, particularly when viewed in the light of the study of the natural history of hydrocephalus by Laurence (1958) who reported that natural spontaneous arrest occurs in almost $45 \%$ of cases. Poor as the overall results are, there were 20 arrests in 46 cases treated by peritoneal shunt $(43.4 \%)$, and we are convinced that peritoneal shunt, combined with excision of the omentum, still has a place in the treatment of hydrocephalus in developing countries.

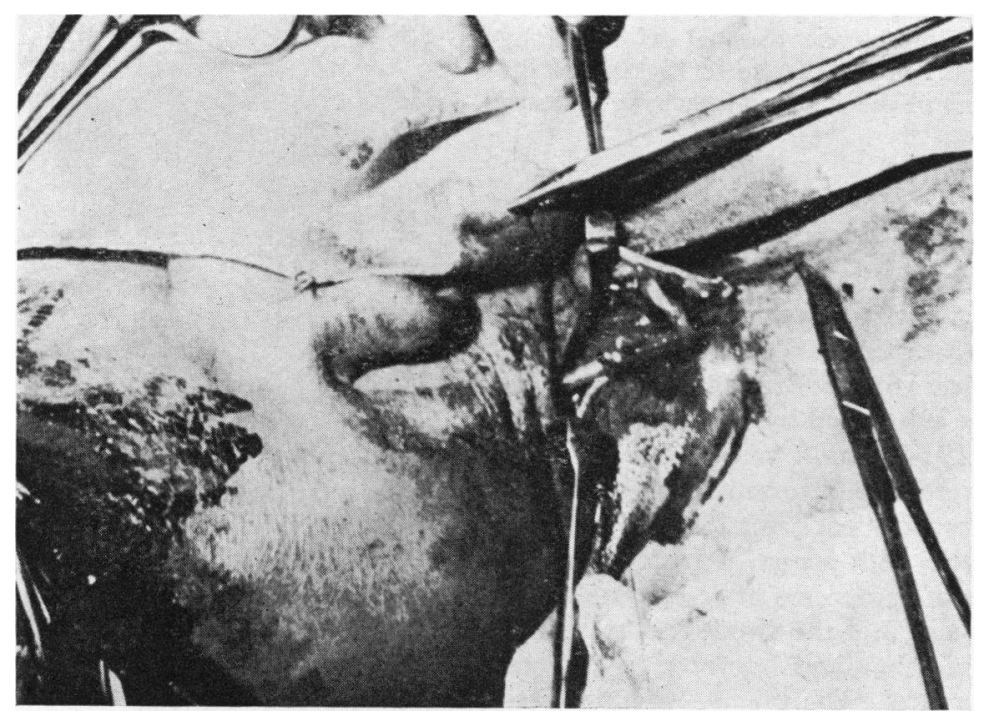

FIG. 9.-The saphenous vein is telescoped on to the portex tube and firmly fixed to it. 


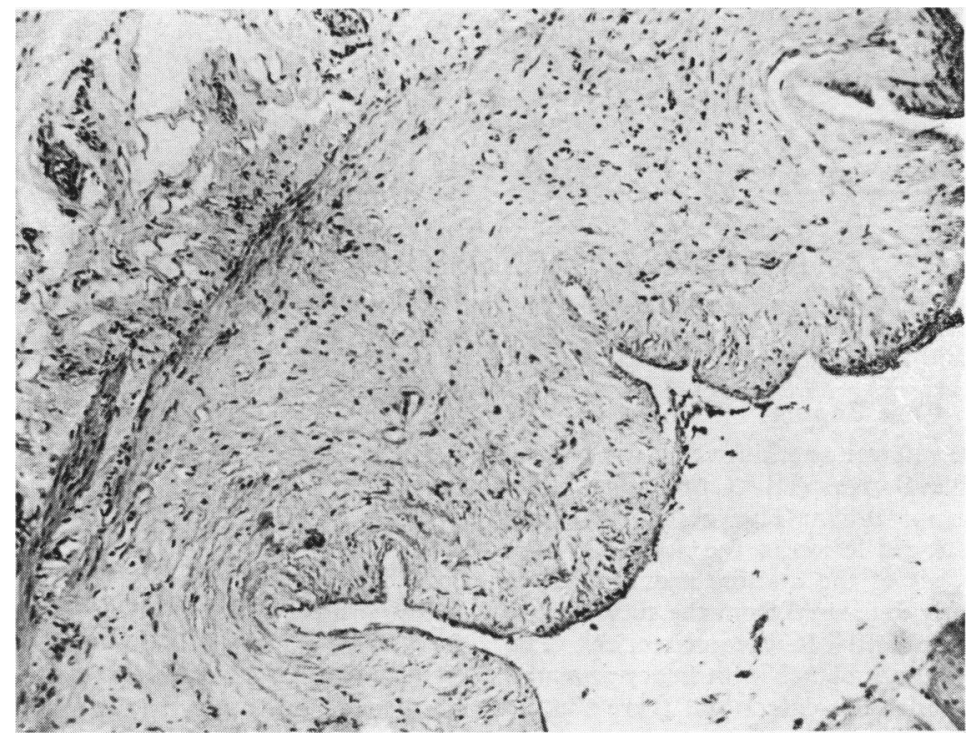

FIG. 10.-Photomicrograph of donor vein 5 weeks after insertion. The intima is intact, and there is no thrombus in the lumen. Though all coats are infiltrated with round cells there is minimal host reaction. $(\times 100$.

It was our dissatisfaction with the results of the conventional procedures open to us that made us try the operation of ventriculo-jugular shunt using a reversed segment of the saphenous vein. In spite of the fact that the surgical principle of the operation is substantiated by experimental data, this procedure has definite disadvantages inherent in it. The anastomosis is a low pressure one, and hence thrombosis could readily occur. To reduce the possibility of thrombosis, the saphenous vein is anastomosed as close to the valve as possible to minimize pooling of blood in the saphenous vein. As part of the host reaction to the homogeneous graft, the saphenous valve may become incompetent with time. One vein was removed 5 weeks after insertion, and histopathology revealed a minimal host reaction, an almost normal intima, and no thrombus in the lumen (Fig. 10). As against these disadvantages there are certain obvious advantages of this procedure. There was no mortality associated with it, and apart from infection in one case, which disappeared when the shunt was dismantled, there was no morbidity. The most important advantage of this operation, however, is that the valve is free and hence economically ideal for all developing countries. There is no prosthetic material in direct contact with the blood-stream, and hence it can be presumed that late bacteraemia will be unlikely.

\section{Summary}

The results of treatment of 70 cases of hydrocephalus by various shunt procedures are discussed. In 15 cases a new operation for hydrocephalus, using a reversed segment of saphenous vein to shunt CSF from the lateral ventricle to the jugular vein, was carried out. Experimental data and operative technique are described. Early results suggest that the procedure may offer hope in developing countries.

I would like to thank Dr. G. K. Karandikar, Dean, J.J. Group of Hospitals and Dr. A. E. deSa, Honorary Principal Medical Officer, Bai Jerbai Wadia Hospital for Children, Bombay, for permission to use hospital records.

\section{REFERENCES}

Benson, C. D., Mustard, W. T., Ravitch, M. M., Snyder, W. H., and Welch, K. J. (1962). Pediatric Surgery. Year Book Medical Publishers, Chicago.

Laurence, K. M. (1958). The natural history of hydrocephalus. Lancet, 2, 1152.

Udwadia, T. E. (1968). Initial experiences with a new operation for hydrocephalus. $\mathcal{F}$. Indian med. Ass., 50, 45.

Correspondence to Dr. T. E. Udwadia, Cook's Building, D. Naoroji Road, Bombay 1, India. 